\title{
Medical Equipment Maintenance under Modern Management
}

\author{
Jinliang Zhang \\ People's Hospital of Zhengzhou, Zhengzhou City, P.R. China \\ tuke126@126.com
}

Corresponding author: Jinliang Zhang

\begin{abstract}
Medical equipment played a more and more important role in clinical diagnosis and treatment. With the development of science and technology, equipment involved science and expanded fields increased the difficulty of equipment maintenance management. Equipment daily maintenance had many problems, for example, hospital attention was not sufficient, maintenance personnel quality was too low, and it was lack of dominating capacity in the maintenance of large equipment maintenance ability and corresponding evaluation standards, management was not standard, and the maintenance training was low. Regarding these short comings, this paper put forwarder the equipment maintenance modernization management measures. Through modern management means not only could effectively improve the quality of work, and also could prolong the service life of medical equipment, improve the work efficiency, and enable the hospital gain more economic benefits.
\end{abstract}

Keywords: Medical Device; Maintenance; Modern Management.

\section{Introduction}

With the progress of technology and constantly improve of medical level, medical apparatus and instruments played a role in the process of medical diagnosis was more and more important. There were various kinds of advanced medical equipment and precision instruments were utilized in medical field. The degree of advanced medical equipment had become a symbol of the hospital instance, scientific development of the medical enterprise was closely related to modern medical sale, and medical sale directly influenced the modernization degree of this hospital diagnosis and treatment. Modern medical devices must have adapted to the modernization of maintenance management, medical apparatus and instruments if often appear problem. It was difficult to provide scientific diagnostic data, the precision was not reliable, could affect the accuracy of medical diagnosis, which affect the safety of patients.

\section{Problems and difficulties existing in the medical equipment maintenance}

In recent years, with the increased numbers of medical equipment, medical apparatus, the quality problem of instruments was becoming more and more obvious. Many hospital was still lag in technology of medical equipment maintenance management, and without clear maintenance system. The maintenance means also need to be improved. With the constant improvement of the medical equipment automation, maintenance personnel quality and technology level also need to constantly improve, and realize modern management means on maintenance management. Currently, hospital existed many problems on medical equipment maintenance, personnel, system, and methods. Below was the medical equipment difference between China and western countries, respectively from innovation.

\subsection{Continuously coming-up of new equipment, lack of leading ability in the large equipment} maintenance

The category and scope of medical device was ever expending, and involving multiple subjects such as computer, machinery, electronics, and optics. It need higher requirement of comprehensive ability of maintenance personnel. In the face of large equipment maintenance, the maintenance staff often were lack of capacity, could only rely on manufacturers. Whether the components price, 
maintenance costs, the maintenance cost control were all in passive position, and had no speaking right.

\subsection{Insufficient hospital attention and low quality of maintenance personnel}

For medical equipment maintenance management, many hospital did not give highly attention on. Large-scale hospital was lack of high-level talents. Part of the small-scale hospital maintenance personnel was not standard, lack of corresponding to modern equipment maintenance, the basis of access to maintenance personnel qualifications, etc. There was no clear regulation. According to related statistics, the front personnel engaged in the maintenance work usually had low education, lack of formal training, laggard modes of thinking, and unable to quickly follow up advanced medical engineering technology. No access, randomly access for researchers could be usually seen in maintenance personnel, who almost did not have time to carefully study the medical equipment maintenance, and brought unnecessary economic losses to the hospital.

Table 1. The medical equipment different situation of China and western countries

\begin{tabular}{|l|l|l|}
\hline & Western countries & China \\
\hline $\begin{array}{l}\text { Overall innovation } \\
\text { ability }\end{array}$ & strong & Weak, strong in few field \\
\hline Industrial division & $\begin{array}{l}\text { Reasonable division, Many small } \\
\text { companies dedicating on research, } \\
\text { large and industrialized company }\end{array}$ & $\begin{array}{l}\text { Division unreasonable division, almost } \\
\text { all company were manufacture } \\
\text { enterprise with poor cooperation } \\
\text { between enterprises. }\end{array}$ \\
\hline $\begin{array}{l}\text { Government } \\
\text { intervention }\end{array}$ & $\begin{array}{l}\text { Supporting public welfare } \\
\text { research, market-oriented project } \\
\text { funding, fund operation were clear } \\
\text { and open. }\end{array}$ & $\begin{array}{l}\text { Performance Government performance } \\
\text { oriented, administrative and formalized } \\
\text { intervention, funding operation were } \\
\text { often opaque }\end{array}$ \\
\hline $\begin{array}{l}\text { Protection on } \\
\text { intellectual property } \\
\text { rights }\end{array}$ & $\begin{array}{l}\text { high attention were attached on } \\
\text { property protection, and } \\
\text { innovation was encouraged and } \\
\text { promoted }\end{array}$ & $\begin{array}{l}\text { property protection was not paid much } \\
\text { attention. Companies had concerns } \\
\text { about innovation and introduction of } \\
\text { overseas advanced technology }\end{array}$ \\
\hline
\end{tabular}

2.3 Not standard management, poor system supporting facility and lack of corresponding evaluation criteria

At present, a lot of hospital medical equipment management was not standard, and without corresponding rules and management system to restrain. Although some hospital had compiled the medical equipment management system, it still belonged to the regulations in the form of the management system. Medical equipment maintenance was very difficult to conduct effective management. There were no corresponding management process, at the same time, also did not establish corresponding medical management assessment mechanism. Work scope was also not clear, technical level was uneven. Although some maintenance personnel could maintain several of equipment, the quality was difficult to reach the standard. In the long run, it was hard to guarantee the normal operation of the medical apparatus and instruments. At the same time, the maintenance quality could not reach the standard, which would affect the accuracy of medical diagnosis, leading to the frequent failure of medical equipment, the credibility of medical diagnosis would be questioned. It not only affect the effect of medical diagnosis, but also affect the treatment of hospital reputation.

\section{4 lagged behind maintenance technology and low input of maintenance training}

With the progress of technology and the improving of the medical level, the upgrading of medical apparatus and instruments were also accelerating pace, increased new medical equipment. Medical equipment automation standards and level are rising. However, some hospital maintenance conditions was still maintained in the traditional maintenance phase. Behindhand means of maintenance and the lack of a precise testing instruments was usually seen in traditional means for maintenance repair, in facing of several of up-to-date medical apparatus and instruments, advanced new equipment [1]. The main cause of this phenomenon was that the hospital leadership did not 
attach great importance to the medical equipment maintenance, and did not willing to spare more expense on the maintenance management, could not see the maintenance quality improvement for the potential economic benefits of hospital.

\section{5 improper daily maintenance in process of medical equipment utilization}

The equipment maintenance of medical equipment was an important process of medical equipment utilization. Regular maintenance of medical equipment was the effective use of medical equipment, the premise of reducing medical equipment failure. The found the problem in the process of maintenance should be timely solved, avoid medical device appear serious fault affects normal diagnosis and treatment. It was hardly to avoid omission. It may affect the regular service of medical equipment, thus influence the service life of medical equipment, and may even ignore the maintenance, and brought the problems to medical equipment.

\section{Countermeasures of medical equipment modernization of maintenance management}

\subsection{Designed needs to meet new management framework}

Hospital had entered hospital management mode with whole life cycle of equipment management, that is to say, equipment requirement toke the equipment procurement as the starting point based on the single equipment, including equipment purchase, usage, maintenance, and the whole process of analysis, equipment purchase expense, equipment maintenance cost of raw materials, maintenance personnel costs, and usage benefit analysis. The ultimate goal was the minimize the equipment life cycle cost, and set the comprehensive benefit as the highest goal. Equipment management covered the equipment tendering procurement, equipment maintenance, equipment, quality control, equipment daily maintenance, and other steps. Equipment should be included in the maintenance of the whole life cycle perspective, as a comprehensive cost reduction to achieve the best benefit.

\subsection{Delicacy management by information management method}

HIS, LIS, PACS information system had already been widely applied in hospital. The application of information technology in the health care industry was very broad, from the hospital online registration, outpatient appointment, expense payment, medicine management, diagnostic equipment, electronic medical records, which all had realized the informatization.

Many hospital had begun to research and develop a complete set of equipment management system, according to the different characteristics of equipment, consumables and attribute classification management. The process of recipients, allocation, transfer, usage, maintenance, recycling, scrap and presentation had been unified management and unified monitoring, then reduced the cost, improved the management efficiency. Nowadays, the maintenance management of maintenance personnel was not only to master technology, at the same time, also want to do the equipment maintenance management of related records, set up repair filing, in order to better grasp the equipment situation, solve the problem of fault in time.

Maintenance management recorded required maintenance management personnel make detailed registration work status of each device, have to be classified management of medical apparatus and instruments, set up the technical filing of detailed according to the different categories to do a good job of records maintenance required [2-4]. In maintenance, the information system convert could be used to make artificial records to establish key equipment basic parameter database, implement daily maintenance tips, data record, on the basis of the complete equipment quality control, performance evaluation, for more in-depth analysis.

\subsection{Promotion in updating concept, improvement on maintenance quality}

Medical equipment maintenance was the the technology requiring stronger intention and maintenance means more complex work [5-8]. Medical equipment maintenance management did not bring direct economic benefits, and the large equipment maintenance was more and more dependent on the upstream manufacturers, more importance in equipment management department was weakened. Equipment management personnel should push hospital leadership to update the concept of maintenance, increase the medical equipment investment and management, and maintenance level, 
could effectively improve the quality and efficiency of maintenance. At the same time, the maintenance level could also greatly reduce labor costs, improve the accuracy of the maintenance and repair rates, shorten the time of medical device failure, improve the distribution of medical apparatus and instruments, and brought more economic benefits [9].

\subsection{A sound management system requiring each department coordination}

To improve hospital equipment service life and reduce the incidence of medical device failure, daily maintenance was very important, and depended on the correct usage of the department of each device and simple maintenance. Before starting the equipment management department shall assist related departments to formulate appropriate maintenance system, completed the maintenance records. Maintenance personnel should also be tested periodically check all sorts of medical apparatus and instruments, clean, easy replacement and calibration related problems of equipment accessories, for some special medical apparatus and instruments, special deal with department staff training, improved the level of maintenance, reduced equipment failure rate and economic benefits.

\subsection{Implement scientific management through database maintenance}

Application of informatization basic parameter database established systematic maintenance records. The detailed maintenance records could provide scientific basic for similar fault management and greatly improve the work efficiency [10-11]. At the same time, through the maintenance records digital classification management, and share information with the user through the network, in order to understand the status of the user of the device in time, timely find problems and reduce the incidence of failure [12-13]. It need more in-depth analysis and forecast to predict the equipment replacement parts.

\section{Conclusion}

With the medical equipment modernization degree becoming higher, the difficulty of medical equipment maintenance management gradually increased as well. Therefore, the hospital leaders should attach great importance to the maintenance of medical instrument management, increase the intensity of maintenance management, strengthen the technical training and the introduction of talent method and improve the skill level of maintenance personnel. Meanwhile, there were other methods should also be adopted, such as increase the investment of maintenance equipment, change the traditional state of medical equipment maintenance management, make effective maintenance management system, strengthen the medical equipment maintenance and maintenance, adapt informatization, diversified approach, and implement modern maintenance management.

\section{References}

[1] Yuewu Wang, Yan Song, Baichun Wu. The construction of hospital equipment maintenance personnel [J]. Chinese Journal of Hospital Administration, 2008,(5):306.

[2] Binning Su, Yidong Zhang. Introduction on medical equipment maintenance management [J]. Friend of Science Amateurs, 2010,(27):100-101.

[3] Feiyi Cui, Huangjing Huang. Discussion on present situation and management of medical equipment maintenance [J]. China Medical Devices, 2011, 26(11):60-64.

[4] Baowen Luo. Discussion on strengthen the management of medical equipment [J]. Chinese Journal of Medical Device, 2009, 22(08):40-41.

[5] Xu Zhang. Medical equipment maintenance inspection and management [J]. Journal of Clinical Rational Drug Use, 2011,4 (30):119-120.

[6] Suzhen Wang, Junyong Wang, Li Wang. China Health Economic Research on the application of modern information technology in the field of drug circulation [J].2011,(07):715-716.

[7] Jie Dai, Lei Su, Luqiong Feng, et al. Research on medical equipment maintenance management [J]. China Medical Equipment, 2010, 7(12):35-38.

[8] Feng Gao, Zheng Li. Advice on medical equipment maintenance management [J]. China Medical Device Information.2011, 17(1):63-65. 
[9] Huan Chen, Zhencai Liu, Xingwang Wang. Deliberation and discussion on large medical equipment maintenance management [J]. China Medical Equipment, 2012, 9(02):52-54.

[10] Guohua Wang. Deliberateness on price of standard medical equipment in China [J]. Price Theory \& Practice.2011, 8 (11):33-34.

[11] Chunhe Zhao. Problem on tradition Chinese medicine decoction piece regulation [J]. Chinese Medical Modern Distance Education of China.2011, 9 (1):164-166.

[12] Yin Tong, Min Wei, Manli Liang. Pollution and protection countermeasures on isolated epidemic area by medical equipment maintenance personnel [J]. Journal of Practical Medical Techniques, 2010, 17 (04):391.

[13] Xianglan Liao, Ping Yang. Discussion on strengthen qualified management of hospital medicine [J]. Medical Information, 2010, 5 (1):99-101. 